\title{
An Ultrasensitive Chemiluminescence Biosensor for Carcinoembryonic Antigen Based on Autocatalytic Enlargement of Immunogold Nanoprobes
}

\author{
Minjia Hao and Zhanfang Ma * \\ Department of Chemistry, Capital Normal University, Beijing 100048, China \\ * Author to whom correspondence should be addressed; E-Mail: mazhanfang@yahoo.com; \\ Tel.: +86-10-6890-2491.
}

Received: 19 October 2012; in revised form: 27 November 2012 / Accepted: 5 December 2012 / Published: 13 December 2012

\begin{abstract}
A sensitive flow injection chemiluminescence assay for carcinoembryonic antigen (CEA) detection based on signal amplification with gold nanoparticles (NPs) is reported in the present work. The sandwich system of CEA/anti-CEA/goat-anti-mouse IgG functionalized $\mathrm{Au}$ nanoparticles was used as the sensing platform. In order to improve detection sensitivity, a further gold enlargement step was developed based on the autocatalytic $\mathrm{Au}$ deposition of gold nanoprobes via the reduction of $\mathrm{AuCl}_{4}{ }^{-}$to $\mathrm{Au}^{0}$ on their surface in the presence of $\mathrm{NH}_{2} \mathrm{OH} \cdot \mathrm{HCl}$. $\mathrm{AuCl}_{4}{ }^{-}$, which is a soluble product of gold nanoprobes, served as an analyte in the CL reaction for the indirect measurement of CEA. Under optimized conditions, the CL intensity of the system was linearly related to the logarithm of CEA concentration in the range of $100 \mathrm{pg} \cdot \mathrm{mL}^{-1}$ to $1,000 \mathrm{ng} \cdot \mathrm{mL}^{-1}$, with a detection limit of $20 \mathrm{pg} \cdot \mathrm{mL}^{-1}$.
\end{abstract}

Keywords: carcinoembryonic antigen; flow injection chemiluminescence; gold nanoparticle; enlargement

\section{Introduction}

The development of highly sensitive methods for detecting cancer biomarkers has great significance for predicting cancer in early stage in modern biochemical and biomedical research [1-3]. Generally, high sensitivity can often be obtained using a signal amplification procedure. Many signal amplification strategies have been reported for sensitive bioanalyte quantification, such as rolling 
circle amplification [4], avidin-biotin amplification [5], and exponential isothermal amplification [6]. However, these approaches usually require extremely complex reagents and intensive protocols. Recently, amplification of immunoassay signals by exploiting the properties of gold nanoparticles (AuNPs) for catalytic growth has emerged as a field attracting significant attention. The commonly used example is silver enhancement, in which AuNPs promote the reduction of silver ions and their deposition on the surface of AuNPs, thereby resulting in further growth of the AuNPs [7]. But it is sensitive to $\mathrm{pH}$, natural light, and chloride ions [8]. Instead of silver staining, using gold salts for catalytic enlargement of AuNPs has solved these issues [9]. This alternative approach has been successfully exploited to develop the detection of IgG by the naked eye [10], target DNA by electrochemical means [11,12] and others [13-15].

Chemiluminscence immunoassay (CLIA), which was first reported in the late 1970s [16], simultaneously combines the high sensitivity of chemiluminescence analysis and the good specificity of immunoassays. Since most biomolecules (such as tumor markers) have no native CL emission, CLIA quantitation is generally realized by indirectly measuring the intensity of chemiluminescence (CL) labels. Recently, methods using nanoparticles (NPs), in particular metal NPs, as CLIA labels have attracted considerable interest [17-19]. Among these, AuNPs have been the subject of wide research efforts directed at gene analysis [20,21] and antibody or antigen detection [22,23] because of their special properties, which include high density, large dielectric constant, and biocompatibility. It has been found that AuNPs can greatly enhance the CL intensity of the luminol- $\mathrm{H}_{2} \mathrm{O}_{2}$ system [24]. Accordingly, a CLIA based on irregular AuNPs was first reported by Li and co-workers [25]. However, the difficulty of controlling the synthesis of irregular nanoparticles may influence the repeatability among different batches and this limits the practical application of this method. Duan et al. [26] established a microplate-compatible CLIA method for the determination of human IgG based on the luminol- $\mathrm{AgNO}_{3}$-gold nanoparticles $\mathrm{CL}$ system. The CL detection is readily influenced by the sediment from the mixture of basic luminol and $\mathrm{AgNO}_{3}$ and has poor sensitivity. In our work, a highly sensitive immunogold amplified FI-CL immunoassay for the detection of CEA is presented through the catalytic precipitation of gold on the immunogold nanoparticles, which combined the intrinsically high sensitivity and good repeatability of FI-CL with the signal enhancement of immunogold enlargement. The present strategy shows excellent promise for ultrasensitive detection of other cancer biomarkers and infectious agents in clinical analysis.

\section{Experimental Section}

\subsection{Reagents and Apparatus}

Polystyrene 96-well microtiter plates (Costar, NY, USA) were used to perform the immunoreactions. CEA and anti-CEA antibody were purchased from R \& D Systems (Minneapolis, MN, USA). Goat-anti-mouse IgG was purchased from Beijing Chengwen Company (Beijing, China). Bovine serum albumin (BSA), $\mathrm{HAuCl}_{4} \cdot 3 \mathrm{H}_{2} \mathrm{O}$ (99.99\%) was bought from Sigma-Aldrich (USA). Trisodium citrate, $\mathrm{NaH}_{2} \mathrm{PO}_{4}, \mathrm{Na}_{2} \mathrm{HPO}_{4}$, and $\mathrm{NaCl}$ are obtained from Beijing Chemical Reagents Company (Beijing, China). The luminol stock solution $\left(2.5 \times 10^{-2} \mathrm{M}\right)$ was prepared by dissolving luminol (obtained from Sigma-Aldrich, USA) in $0.1 \mathrm{M} \mathrm{NaOH}$ solution and stored in a dark place. The buffers used were as 
follows: (A) coating buffer, $0.05 \mathrm{M}$ carbonate/bicarbonate buffer solution, $\mathrm{pH} 9.6$; (B) blocking buffer, $1 \%\left(\mathrm{w} / \mathrm{v}, \mathrm{g} \cdot \mathrm{mL}^{-1}\right) \mathrm{BSA}$ in $0.01 \mathrm{M}$ sodium phosphate buffered saline with $0.05 \%(\mathrm{v} / \mathrm{v})$ Tween 20 (PBST-BSA), pH 7.4. The blocking buffer was stored at $4{ }^{\circ} \mathrm{C}$ and used within a week; (C) washing buffer, $0.01 \mathrm{M}$ PBS with $0.05 \%$ (v/v) Tween 20, $\mathrm{pH} 7.4$; In all the procedures, the water used was purified through an Olst ultrapure K8 apparatus (Olst, Ltd., China, resistivity >18 M $\Omega$ ). All other reagents were of analytical reagent grade and used as purchased without further purification. The CL intensity was measured and recorded with an Ultra-weak luminescence analyzer and software BPCL-T15 (Institute of Biophysics, Academic Sinica, Beijing, China). Two peristaltic pumps were used to deliver all the chemicals. A six way injection valve fitted with a $100 \mu \mathrm{L}$ sample loop was used for the injection of the sample solution. PTFE tubing (1.0 $\mathrm{mm}$ i.d.) was used to connect all components in the flow system. Transmission electron microscopy (TEM) was performed with a JEOL-100CX electronmicroscope (Jeol, Japan) under $80 \mathrm{kV}$ accelerating voltage.

\subsection{Preparation of Au Nanoparticles (NPs)}

A solution of $15 \mathrm{~nm}$ AuNPs was synthesized according to a literature procedure [27] with slight modifications. Briefly, $5.0 \mathrm{~mL}$ of $1 \%$ trisodium citrate was quickly added to $100 \mathrm{~mL}$ of boiling $0.01 \%$ $\mathrm{HAuCl}_{4}$. Solution under reflux was stirred for $10 \mathrm{~min}$, during which the color changed to red. After being slowly cooled down to room temperature, the solution was centrifuged to remove impurities and ions, and then diluted to $100 \mathrm{~mL}$. The AuNPs have an average diameter of ca. $15 \mathrm{~nm}$.

\subsection{Preparation of AuNPs-Labeled Goat-Anti-Mouse IgG}

The preparation of AuNPs-labeled goat-anti-mouse IgG was performed according to the modification in literature [28]. The $\mathrm{pH}$ of the AuNPs was adjusted to 8.0 with $0.1 \mathrm{M} \mathrm{Na}_{2} \mathrm{CO}_{3}$. Precisely, $1.0 \mathrm{~mL}$ of $550 \mu \mathrm{g} \cdot \mathrm{mL}^{-1}$ goat-anti-mouse $\mathrm{IgG}(10 \%$ more than the minimum amount, which was determined using a flocculation test) was added to $5 \mathrm{~mL}$ of $\mathrm{pH}$-adjusted AuNPs, followed by incubation at room temperature for $30 \mathrm{~min}$. Afterward, 5\% BSA was added to a final concentration of $1 \%$ with stirring about $5 \mathrm{~min}$. To remove the excess of antibody, the conjugates were centrifuged at $10,000 \mathrm{rpm}$ for $10 \mathrm{~min}$, and the soft sediment was resuspended in $0.01 \mathrm{M}$ PBS containing $1 \%$ BSA. It can be used directly or stored in $0.01 \mathrm{M}$ PBS buffer with $50 \%$ glycerol for several months at $-20{ }^{\circ} \mathrm{C}$.

\subsection{Immunoassay Procedure}

The assay was performed in a polystyrene 96-well microtiter plate. Initially, $200 \mu \mathrm{L}$ of serially diluted human CEA dilutions in coating buffer were coated on wells of the plate overnight at $4{ }^{\circ} \mathrm{C}$. The unbound antigen was washed off three times with $300 \mu \mathrm{L}$ of washing buffer and the uncoated active sites of polystyrene substrate were saturated with $300 \mu \mathrm{L}$ of blocking buffer for $1 \mathrm{~h}$ at $37^{\circ} \mathrm{C}$, in which BSA was used as a blocking agent to prevent nonspecific adsorption of the antibody in the next step. Afterward, $200 \mu \mathrm{L}$ of $5 \mu \mathrm{g} \cdot \mathrm{mL}^{-1}$ anti-CEA antibody was added into the wells and incubated for $2 \mathrm{~h}$ at $37{ }^{\circ} \mathrm{C}$. The wells were washed three times with washing buffer followed by addition of $200 \mu \mathrm{L}$ AuNPs-labeled goat-anti-mouse IgG. Finally the wells were washed thoroughly with washing buffer 
(three times) and pure water (three times). Then, the wells were immediately treated with $200 \mu \mathrm{L}$ per well of a mixture of $0.01 \% \mathrm{HAuCl}_{4}$ and $0.4 \mathrm{mM} \mathrm{NH} \mathrm{H}_{2} \mathrm{OH} \cdot \mathrm{HCl}$ in a dark for $2 \mathrm{~min}$ at $30^{\circ} \mathrm{C}$.

\subsection{Standard Procedures for the FI-CL Detection}

Metallic gold on enhanced plates were washed three times with $300 \mu \mathrm{L}$ of pure water, dried, and dissolved with $200 \mu \mathrm{L}$ of $2.0 \% \mathrm{HNO}_{3}-3.4 \% \mathrm{HCl}$ for three hours at room temperature to ensure that the $\mathrm{Au}$ nanoparticles were completely dissolved. Solutions were then transferred to $1.5 \mathrm{~mL}$ centrifuge tubes and $200 \mu \mathrm{L} \mathrm{H} \mathrm{H}_{2} \mathrm{O}$ and $75 \mu \mathrm{L} 0.1 \mathrm{M}$ sodium tartrate $\left(\mathrm{C}_{4} \mathrm{H}_{4} \mathrm{O}_{6} \mathrm{Na}_{2}\right)$ were added to each sample in turn. Then $1.0 \mathrm{M} \mathrm{NaOH}$ was added to the $\mathrm{AuCl}_{4}{ }^{-}$solutions to adjust $\mathrm{pH}$. As shown in Figure $1, \mathrm{AuCl}_{4}{ }^{-}$ was reacted with the mixture of luminol and $\mathrm{H}_{2} \mathrm{O}_{2}$ in the flow cell to produce the CL signal. The CL signals were monitored with a photomultiplier tube adjacent to the flow cell.

Figure 1. Schematic diagram of flow injection CL system.

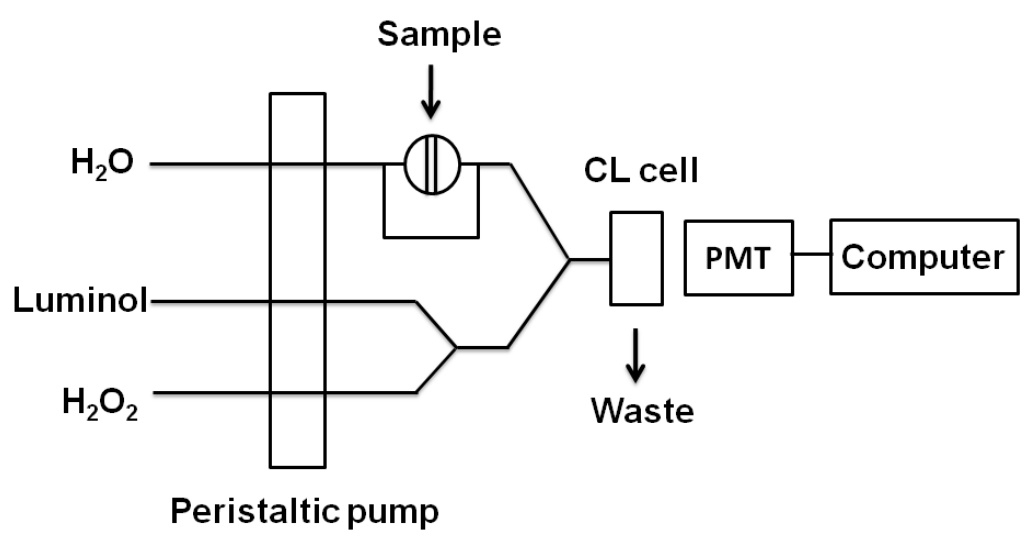

\section{Results and Discussion}

\subsection{Principles of the Experiment}

A schematic representation of the detection principle of this noncompetitive CL immunoassay is shown in Scheme 1. The human CEA analyte is first immobilized on a 96-well polystyrene microtiter plate. The mouse-anti-CEA as primary antibody is then captured by the CEA and sandwiched by a goat-anti-mouse IgG secondary antibody labeled with colloidal gold. After that, we used a method for enlargement of colloidal Au nanoparticles called "seeding", based on the colloidal Au surface-catalyzed reduction of $\mathrm{Au}^{3+}$ by $\mathrm{NH}_{2} \cdot \mathrm{OH}$. While $\mathrm{NH}_{2} \cdot \mathrm{OH}$ is thermodynamically capable of reducing $\mathrm{Au}^{3+}$ to bulk metal, the reaction is dramatically accelerated by Au surfaces. As a result, no new particle nucleation occurs in solution, and all added $\mathrm{Au}^{3+}$ goes into production of larger particles. In this case, Au NPs are specifically enlarged by $\mathrm{HAuCl}_{4}$ and $\mathrm{NH}_{2} \mathrm{OH} \cdot \mathrm{HCl}$ for 2 min [9]. Next, the AuNPs are dissolved in a $2.0 \% \mathrm{HNO}_{3}-3.4 \% \mathrm{HCl}$ solution and the gold ions $\left(\mathrm{AuCl}_{4}{ }^{-}\right)$were stripped out from the solid polystyrene substrate surface. The concentration of CEA was quantified based upon the concentration of dissolved $\mathrm{AuCl}_{4}^{-}$, which was quantified by the CL intensity. A comparison of analytical performance before and after gold amplification was also investigated and the detailed optimization of the gold amplified FI-CL immunoassay is reported in the following sections. 
Scheme 1. Picture representation of the proposed CL immunoassay and colloidal gold labels enlargement for human CEA.
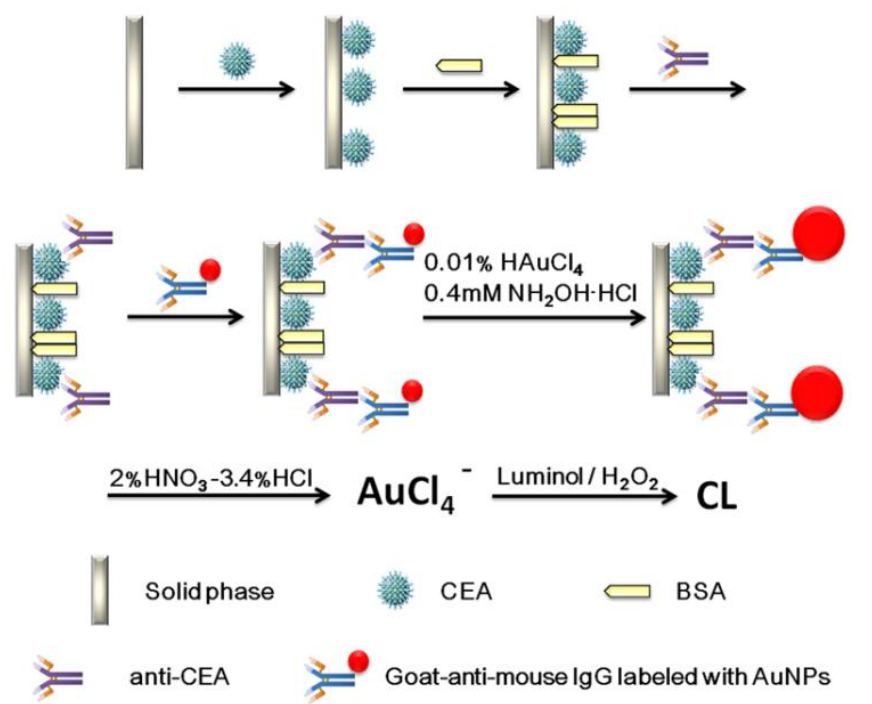

\subsection{Dissolution of Gold Nanoparticles}

The AuNPs used in this work before and after enlargement with $\mathrm{HAuCl}_{4}$ and $\mathrm{NH}_{2} \mathrm{OH} \cdot \mathrm{HCl}$ are shown in Figure 2A,B. To detect the enlarged colloidal gold label by CL, the gold was dissolved to form $\mathrm{AuCl}_{4}{ }^{-}$, which can catalyze the luminol- $\mathrm{H}_{2} \mathrm{O}_{2} \mathrm{CL}$ reaction. As the aqua regia $\left(16.0 \% \mathrm{HNO}_{3}-27 \% \mathrm{HCl}\right)$ resulted in a high CL background, dilution of the aqua regia was used to dissolve the colloidal gold. Therefore, the effect of the dissolution reagent concentration on CL intensity was investigated. The signal/noise ratio increased with increasing dissolution reagent concentration and reached a maximum value at 1:7 dilution of aqua regia $\left(2.0 \% \mathrm{HNO}_{3}-3.4 \% \mathrm{HCl}\right)$, as shown in Figure 3 . It is possible that AuNPs could not be completely dissolved when the concentration of the dissolution reagent was lower than the 1:7 dilution of aqua regia. The signal/noise ratio decreased gradually when it exceeded 1:7 and it is likely that the strong ionic strength in the solution induces an increase in the CL background intensity when a much higher concentration of dissolution reagent is used. Thus, the 1:7 dilution of aqua regia was used as the optimum dissolution reagent for the CL assay.

Figure 2. TEM images of colloidal gold before (A) and after (B) 2 min gold amplification.
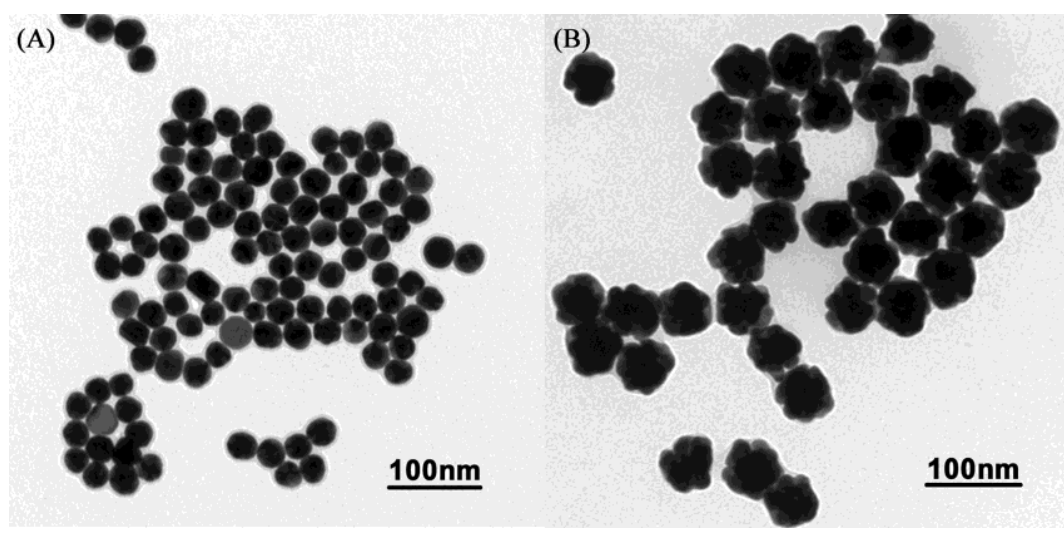
Figure 3. Signal/noise ratio versus the concentration of aqua regia. Experimental conditions: $20 \mu \mathrm{L}$ gold nanoparticles $(15 \mathrm{~nm})$ was dissolved in $200 \mu \mathrm{L}$ of different concentrations of aqua regia, then $200 \mu \mathrm{L} \mathrm{H}_{2} \mathrm{O}, 75 \mu \mathrm{L} 0.1 \mathrm{M}$ sodium tartrate and $1.0 \mathrm{M}$ $\mathrm{NaOH}$ were added to adjust the $\mathrm{pH}$ of the solution to 4 .

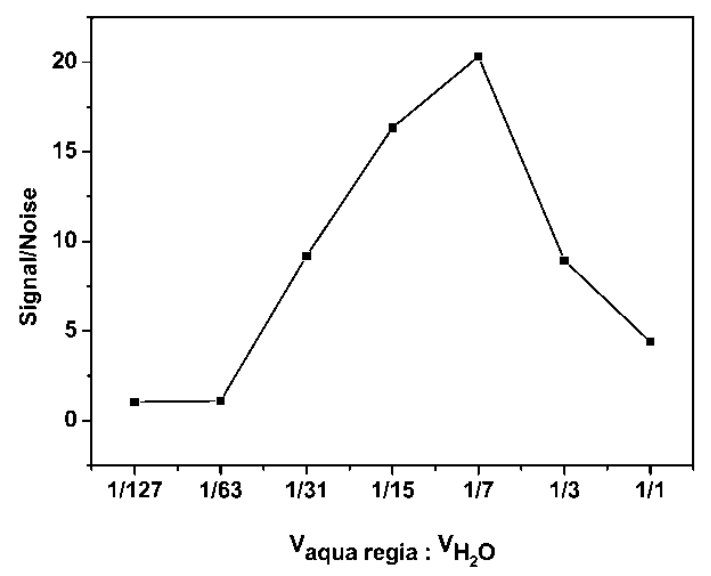

The catalytic activity of $\mathrm{AuCl}_{4}{ }^{-}$on the luminol- $\mathrm{H}_{2} \mathrm{O}_{2} \mathrm{CL}$ reaction is greatly influenced by the $\mathrm{pH}$ of the $\mathrm{AuCl}_{4}{ }^{-}$solution. Therefore, the effect of $\mathrm{AuCl}_{4}{ }^{-} \mathrm{pH}$ on CL intensity was investigated by using $1.0 \mathrm{M} \mathrm{NaOH}$ and $0.1 \mathrm{M} \mathrm{C}_{4} \mathrm{H}_{4} \mathrm{O}_{6} \mathrm{Na}_{2}$ to adjust the acidity of the solution after dissolving the AuNPs with 1:7 (v/v) aqua regia. As shown in Figure 4, the signal/noise ratio increased with increasing $\mathrm{pH}$ of sample solution because the blank CL intensity decreased with increasing sample $\mathrm{pH}$ below 4.0, reaching the highest value at $\mathrm{pH} 4.0$. However, when the $\mathrm{pH}$ of the sample was higher than 4.0, the signal/noise ratio decreased. The cause is that the stability of $\mathrm{AuCl}_{4}{ }^{-}$has been destroyed. Therefore, $\mathrm{pH} 4.0$ was chosen as the optimum $\mathrm{pH}$ value for the CL measurement.

Figure 4. Signal/noise ratio versus the $\mathrm{pH}$ of sample. Experimental conditions: $20 \mu \mathrm{L}$ gold nanoparticles $(15 \mathrm{~nm})$ was dissolved in $200 \mu \mathrm{L}$ of aqua regia $\left(2.0 \% \mathrm{HNO}_{3}-3.4 \% \mathrm{HCl}\right)$, then $200 \mu \mathrm{L} \mathrm{H}_{2} \mathrm{O}, 75 \mu \mathrm{L} 0.1 \mathrm{M}$ sodium tartrate and $1.0 \mathrm{M} \mathrm{NaOH}$ were added to adjust the $\mathrm{pH}$ of the solution.

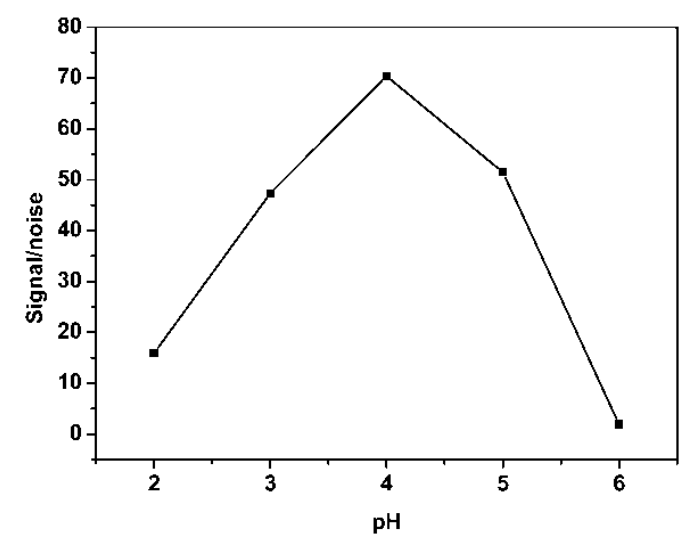

\subsection{Optimization of the CL Detection Conditions}

To optimize the proposed CL assay, the effects of luminol and $\mathrm{H}_{2} \mathrm{O}_{2} \mathrm{pH}$ on the CL intensities were studied. The optimization of the $\mathrm{pH}$ value of luminol was investigated over the $\mathrm{pH}$ range 10.0-13.0. 
The result indicates that the signal/noise ratio had a maximum at $\mathrm{pH} 12.5$. The effects of luminol and $\mathrm{H}_{2} \mathrm{O}_{2}$ concentration on the $\mathrm{CL}$ intensity of the sample and blank were also examined. This indicated that the $\mathrm{CL}$ intensity increased as the luminol and $\mathrm{H}_{2} \mathrm{O}_{2}$ concentrations were increased but the CL intensity of the blank became very high when the concentration of luminol exceeded $1.0 \times 10^{-4} \mathrm{M}$ and led to poor reproducibility. Considering the CL intensity and the consumption of the reagents, $7.5 \times 10^{-5} \mathrm{M}$ and $0.01 \mathrm{M} \mathrm{H}_{2} \mathrm{O}_{2}$ were chosen for subsequent work (data not shown).

\subsection{Analytical Performance}

Under the optimum conditions described above, the relationship between CEA concentration and $\mathrm{CL}$ intensity was investigated. The results showed that the CL intensities of luminol- $\mathrm{H}_{2} \mathrm{O}_{2}-\mathrm{AuCl}_{4}{ }^{-}$ increased with the increase of concentration of the CEA ranging from $10 \mathrm{pg} \cdot \mathrm{mL}^{-1}$ to $1 \mu \mathrm{g} \cdot \mathrm{mL}^{-1}$ (Figure 5A). The linear range for CEA was $100 \mathrm{pg} \cdot \mathrm{mL}^{-1}$ to $1 \mu \mathrm{g} \cdot \mathrm{mL}^{-1}$ with the equation of $\lg [\mathrm{y}]=3.8077+0.12151 \mathrm{~g}[\mathrm{x}]$ ( $\mathrm{y}$ is the CL intensity; $\mathrm{x}$ is the concentration of $\mathrm{CEA}, \mathrm{ng} \cdot \mathrm{mL}^{-1} ; \mathrm{n}=3$, $\mathrm{R}=0.9892$; Figure 5B). The relative standard deviations for $10 \mathrm{pg} \cdot \mathrm{mL}^{-1}$ and $1 \mu \mathrm{g} \cdot \mathrm{mL}^{-1}$ of CEA were $0.44 \%$ and $4.7 \%$, respectively $(\mathrm{n}=3)$. The detection limit was $20 \mathrm{pg} \cdot \mathrm{mL}^{-1}$. Table 1 shows the comparison between the proposed CL method and general immunoassay formats for determination of CEA. It can be seen that the proposed CLIA is competitive with or better than other immunoassay formats and has the advantage of simple instrumentation.

Figure 5. Relationship between the concentration of CEA and CL intensity after the immunogold enlargement.

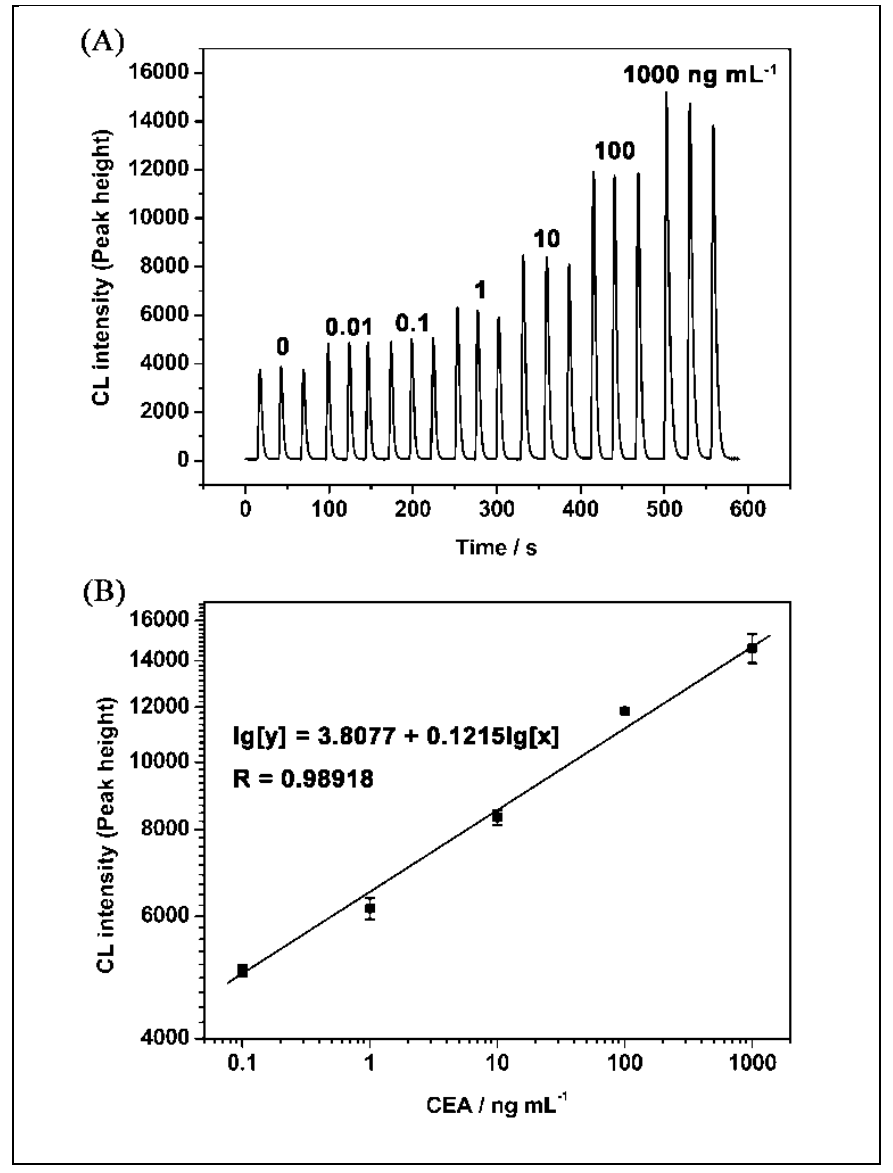


Table 1. Comparison of various immunoassay methods for CEA determination.

\begin{tabular}{cccc}
\hline Label & Analytical method & Detection limit $\left.\mathbf{( n g} \cdot \mathbf{m L}^{-\mathbf{1}}\right)$ & Reference \\
\hline HRP & ELISA & 0.048 & {$[29]$} \\
HRP & Chemiluminescence immunoassay & 0.5 & {$[30]$} \\
HRP & Enzyme-linked immunoassay & 3.0 & {$[31]$} \\
AuNPs & ICPMS immunoassay after silver amplification & 0.03 & {$[32]$} \\
AuNPs & Electrochemical immunoassay & 0.27 & {$[33]$} \\
AuNPs & Electrochemical immunoassay & 0.57 & {$[34]$} \\
AuNPs & Chemiluminescence immunoassay after & 0.02 & this work \\
AuNPs & gold enlargement & 1.0 & this work \\
\hline
\end{tabular}

\section{Conclusions}

The feasibility of a highly sensitive FI-CL immunoassay, based on the quantitative enlargement of immunogold tags, has been demonstrated. AuNPs are dissolved into $\mathrm{Au}^{3+}$, which catalyzes the luminol chemiluminescence (CL) reaction. The CL intensity, which is proportional to the amount of CEA, could be greatly enhanced. The response of this immunosensor was linear from $0.1-1,000 \mathrm{ng} \cdot \mathrm{mL}^{-1}$ with a LOD of $20 \mathrm{pg} \cdot \mathrm{mL}^{-1}(\mathrm{~S} / \mathrm{N}=3)$. The procedure involved in this work is simple, low cost and rapid. The proposed method can provide high sensitivity, a wide linear range and represents a new approach to the ultrasensitive determination of other bioactive molecules for early disease diagnosis.

\section{Acknowledgments}

This study was supported by Funding Project for Academic Human Resources Development in Institutions of Higher Learning under the Jurisdiction of Beijing Municipality (PHR20100718).

\section{References}

1. Wu, J.; Tang, J.; Dai, Z.; Yan, F.; Ju, H.; Murr, E.N. A disposable electrochemical immunosensor for flow injection immunoassay of carcinoembryonic antigen. Biosens. Bioelectron. 2006, 22, 102-108.

2. Meng, J.; Meng, J.; Duan, J.H.; Kong, H.; Li, L.; Wang, C.; Xie, S.S.; Chen, S.C.; Gu, N.; $\mathrm{Xu}, \mathrm{H} . Y$; et al. Carbon nanotubes conjugated to tumor lysate protein enhance the efficacy of an antitumor immunotherapy. Small 2008, 9, 1364-1370.

3. Shi, W.T.; Ma, Z.F. A novel label-free amperometric immunosensor for carcinoembryonic antigen based on redox membrane. Biosens. Bioelectron. 2001, 26, 3068-3071.

4. Cheng, Y.Q.; Zhang, X.; Li, Z.P.; Jiao, X.X.; Wang, Y.C.; Zhang, Y.L. Highly sensitive determination of microRNA using target-primed and branched rolling-circle amplification. Angew. Chem. Int. Ed. 2009, 48, 3268-3272.

5. Tei, L.; Barge, A.; Crich, S.G.; Pagliarin, R.; Negri, V.; Ramella, D.; Cravotto, G.; Aime, S. Target visualization by MRI using the avidin/biotin amplification route: Synthesis and testing of a biotin-Gd-DOTA monoamide trimer. Chem. Eur. J. 2010, 16, 8080-8087. 
6. Jia, H.X.; Li, Z.P.; Liu, C.H.; Cheng, Y.Q. Ultrasensitive detection of microRNAs by exponential isothermal amplification. Angew. Chem. Int. Ed. 2010, 49, 5498-5501.

7. Chen, Z.P.; Luo, Y.; Qu, B.; Jiang, J.H.; Zhang, X.B.; Shen, G.L.; Yu, R.Q. Successively amplified electrochemical immunoassay based on biocatalytic deposition of silver nanoparticles and silver enhancement. Biosens. Bioelectron. 2007, 23, 485-491.

8. Owen, G.R.; Meredith, D.O.; Gwyrm, I.A.; Richards, R.G. Enhancement of immunogold-labellled focal adhesion sites in fibroblasts cultured on metal substrates: Problems and solutions. Cell Biol. Int. 2001, 25, 1251-1259.

9. Brown, K.R.; Natan, M.J. Hydroxylamine seeding of colloidal Au nanoparticles in solution and on surfaces. Langmuir 1998, 14, 726-728.

10. Ma, Z.F.; Sui, S.F. Naked-eye sensitive detection of immunoglubulin G by enlargement of $\mathrm{Au}$ nanoparticles in vitro. Angew. Chem. Int. Ed. 2002, 41, 2176-2179.

11. Du, B.A.; Li, Z.P.; Liu, C.H. One-step homogeneous detection of DNA hybridization with gold nanoparticle probes by using a linear light-scattering technique. Angew. Chem. Int. Ed. 2006, 45, 8022-8025.

12. Wang, K.L.; Qiu, X.; Dong, C.Q.; Ren, J.C. Single-molecule technology for rapid detection of DNA hybridization based on resonance light scattering of gold nanoparticles. ChemBioChem 2007, 8, 1126-1129.

13. Ma, Z.F.; Li, J.R.; Jiang, L.; Yang, M.S.; Sui, S.F. High sensitive DNA detection amplified by enlarging Au-nanoparticles in situ. Chem. Lett. 2002, 3, 328-329.

14. Ma, Z.F.; Wu, J.L.; Zhou, T.H.; Chen, Z.H.; Dong, Y.G.; Tang, J.T.; Sui, S.F. Detection of human lung carcinoma cell using quartz crystal microbalance amplified by enlarging Au nanoparticles in vitro. New J. Chem. 2002, 261, 795-1798.

15. Ma, Z.F.; Liang, R.; Jiang, W.L.; Zhou, T.H.; Chen, Z.H.; Duan, M.X.; Tang, J.T.; Sui, S.F. Colorimetric detection of human lung carcinoma cell by enlarging Au-nanoparticles in situ. Chem. Lett. 2002, 6, 570-571.

16. Lamminmäki, U.; Westerlund-Karlsson, A.; Toivola, M.; Saviranta, P. A New Reliable Chemiluminescence Immunoassay (CLIA) For Prostaglandin $\mathrm{E}_{2}$ Using Enhanced Luminol as Substrate. Prostaglandins 1996, 52, 385-401.

17. Wang, Z.P.; Li, J.; Liu, B.; Li, J.H. CdTe nanocrystals sensitized chemiluminescence and the analytical application. Talanta 2009, 77, 1050-1056.

18. Ding, C.F.; Zhong, H.; Zhang, S.S. Ultrasensitive flow injection chemiluminescence detection of DNA hybridization using nanoCuS tags. Biosens. Bioelectron. 2008, 23, 1314-1318.

19. Chen, L.L.; Zhang, Z.J.; Zhang, P.; Zhang, X.M.; Fu, A.H. An ultra-sensitive chemiluminescence immunosensor of carcinoembryonic antigen using HRP-functionalized mesoporous silica nanoparticles as labels. Sens. Actuators B Chem. 2011, 155, 557-561.

20. Qi, Y.Y.; Li, B.X.; Zhang, Z.J. Label-free and homogeneous DNA hybridization detection using gold nanoparticles-based chemiluiminescence system. Biosens. Bioelectron. 2009, 24, 3581-3586.

21. Xu, Q.F.; Liu, J.; He, Z.K.; Yang, Y. Superquenching acridinium ester chemiluminescence by gold nanoparticles for DNA detection. Chem. Commun. 2010, 46, 8800-8802. 
22. Yang, X.Y.; Guo, Y.S.; Bi, S.; Zhang, S.S. Ultrasensitive enhanced chemiluminescence enzyme immunoassay for the determination of $\alpha$-fetoprotein amplified by double-codified gold nanoparticles labels. Biosens. Bioelectron. 2009, 24, 2707-2711.

23. Sun, X.B.; Ma, Z.F. Highly stable electrochemical immunosensor for carcinoembryonic antigen. Biosens. Bioelectron. 2012, 35, 470-474.

24. Zhang, Z.F.; Cui, H.; Lai, C.Z.; Liu, L.J. Gold nanoparticle-catalyzed luminol chemiluminescence and its analytical applications. Anal. Chem. 2005, 77, 3324-3329.

25. Wang, Z.P.; Hu, J.Q.; Jin, Y.; Yao, X.; Li, J.H. In situ amplified chemiluminescent detection of DNA and immunoassay of IgG using special-shaped gold nanoparticles as label. Clin. Chem 2006, 52, 1958-1961.

26. Duan, C.F.; Yu, Y.Q.; Cui, H. Gold nanoparticle-based immunoassay by using non-stripping chemiluminescence detection. Analyst 2008, 133, 1250-1255.

27. Wang, R.M.; Di, J.; Ma, J.; Ma, Z.F. Highly sensitive detection of cancer cells by electrochemical impedance spectroscopy. Electrochim. Acta 2012, 61, 179-184.

28. Li, H.Q.; Wang, C.H.; Ma, Z.F.; Su, Z.M. Colorimetric detection of immunoglobulin G by use of functionalized gold nanoparticles on polyethylenimine film. Anal. Bioanal. Chem. 2006, 384, 1518-1524.

29. Liu, M.Y.; Jia, C.P.; Jin, Q.H.; Lou, X.H.; Yao, S.H.; Xiang, J.Q.; Zhao, J.L. Novel colorimetric enzyme immunoassay for the detection of carcinoembryonic Antigen. Talanta 2010, 81, 1625-1629.

30. Lin, J.H.; Yan, F.; Ju, H.X. Noncompetitive enzyme immunoassay for carcinoembryonic antigen by flow injection chemiluminescence. Anal. Chim. Acta 2004, 341, 109-115.

31. Terenghi, M.; Elviri, L.; Careri, M.; Mangia, A.; Lobinski, R. Multiplexed determination of protein biomarkers using metal-tagged antibodies and size exclusion chromatography-inductively coupled plasma mass spectrometry. Anal. Chem. 2009, 81, 9440-9448.

32. Liu, R.; Liu, X.; Tang, Y.R.; Wu, L.; Hou, X.D.; Lv, Y. Highly sensitive immunoassay based on immunogold-silver amplification and inductively coupled plasma mass spectrometric detection. Anal. Chem. 2011, 83, 2330-2336.

33. Fu, Y.Z.; Yuan, R.; Chai, Y.Q.; Zhang, Y.; Peng, Y.G. Electrochemical immunoanalysis for carcinoembryonic antigen based on multilayer architectures of gold nanoparticles and polycation biomimetic interface on glassy carbon electrode. Electroanalysis 2006, 18, 2451-2457.

34. Li, N.; Zhao, H.W.; Yuan, R.; Peng, K.F.; Chai, Y.Q. An amperometric immunosensor with a DNA polyion complex membrane/gold nanoparticles-backbone for antibody immobilization. Electrochim. Acta 2008, 54, 235-241.

(C) 2012 by the authors; licensee MDPI, Basel, Switzerland. This article is an open access article distributed under the terms and conditions of the Creative Commons Attribution license (http://creativecommons.org/licenses/by/3.0/). 